\title{
EL CATÁLOGO DE MANUSCRITOS LATINOS, CASTELLANOS, GRIEGOS Y HEBREOS DE LA BIBLIOTECA DE EL ESCORIAL ELABORADO POR FRANCISCO PÉREZ BAYER
}

\author{
Bárbara Barberá Matías \\ Departamento de Historia Medieval y Ciencias y Técnicas Historiográficas. \\ Universitat de València
}

\begin{abstract}
Resumen: Francisco Pérez Bayer (1711-1794), catedrático de hebreo de la Universidad de Salamanca, preceptor de los hijos de Carlos III y bibliotecario mayor de la Real Biblioteca desde 1783, elaboró el catálogo de los manuscritos latinos, castellanos, griegos y hebreos de la Real Biblioteca del Monasterio de El Escorial por mandato de Carlos III. En el presente artículo se analizan las circunstancias en las que se produjo la redacción de dicho catálogo, ofreciendo además una descripción del mismo.
\end{abstract}

Palabras clave: S. XVIII, catálogo, manuscrito, El Escorial, biblioteca, Francisco Pérez Bayer.

The catalog of the latin, spanish, greek and hebrew manuscripts of the library of El Escorial by Francisco Pérez Bayer

Abstract: Francisco Pérez Bayer (1711-1794), who was professor in the University of Salamanca, tutor of the children of King Charles III and librarian of de Royal Library since 1783, prepared, by royal comand, a catalogue of latin, spanish, greek and hebrew manuscripts of the Royal Library of the Monastery of El Escorial. In the next article we show the circumstances in which this catalogue was made and study the situation of its production offering a detailed description.

Key words: century 18th, catalog, manuscripts, El Escorial, library, Francisco Pérez Bayer.

En el s. XVI Felipe II se propuso crear una gran biblioteca a imagen y semejanza de las principales librerías europeas del momento. Para llevar a cabo su proyecto siguió el consejo de personalidades eruditas como la de Juan Páez de Castro, que en el memorial sobre la utilidad de juntar una buena biblioteca, dirigido a dicho monarca, señalaba las ventajas de contar con este tipo de instituciones: "Por causa de las librerías perdieron muchas naciones el nombre de barbaros y muchas ciudades fueron frequentadas de los principales hombres del mundo y se ennoblecieron con estudios y universidades. Las librerías son causa, que se haga amistad, y concordia entre diversas naciones por vía de letras" (Páez de Castro, 1749?, p. 24).

Esta magna biblioteca se ubicó en el Real Monasterio de San Lorenzo de El Escorial, cuya obra comenzó en 1563. Los primeros libros llegaron al monasterio dos años después y en 1575 se produjo la entrega oficial, siendo la orden de los jerónimos la encargada de regentar la librería. Felipe II consiguió reunir colecciones tan importantes como las proceden-

Data de recepció: 6 de setembre de 2016 / Data d'acceptació: 28 de gener de 2017. 
tes de las bibliotecas de Diego Hurtado de Mendoza o Antonio Agustín ${ }^{1}$. El resultado fue una gran biblioteca de carácter público, es decir, que podía ser consultada previo permiso del monarca, cuyos fondos contenían, siguiendo el proyecto planteado por Felipe II, "obras de teología y filosofía y además todas las que son materias de las siete artes liberales, escritas en las lenguas clásicas antiguas, latín, griego y hebreo, como en las modernas, incluyendo, cosa rara en aquel tiempo, las obras de árabe de ciencias y medicina" (Andrés, 1985, p. 563); además de una colección de cuadros y dibujos de los principales autores y toda suerte de instrumentos científicos y matemáticos, globos terrestres, mapas... Según Gregorio de Andrés, fue la primera biblioteca renacentista de España (Andrés, 1985, p. 561).

Después del reinado de Felipe II la adquisición de libros se ralentizó y en junio de 1671 un incendio producido en el monasterio afectó a la biblioteca, perdiéndose un gran número de volúmenes. Tras el incidente los manuscritos, inicialmente colocados en el llamado salón de verano (hoy en día la sala de investigadores), fueron trasladados al salón alto, ubicado encima del salón principal, donde permanecieron hasta que en 1862 fueron trasladados a su actual ubicación por el Padre Antonio Claret (Justel Calabozo, 1978, p. 65). En palabras del Padre Núñez los libros quedaron "como selva inculta que nadie se atrevía a pasear" (Zarco Cuevas, 1924, p. LXXIII).

El objetivo del presente trabajo es analizar y describir el catálogo de los manuscritos latinos, castellanos, griegos y hebreos de la biblioteca de El Escorial hecho por Francisco Pérez Bayer, como parte de una tradición catalográfica que comienza en el s. XVII y que se vio impulsada en el s. XVIII por los bibliotecarios de la Real Biblioteca. Pérez Bayer participó en este movimiento caracterizado por su erudición con la elaboración de este catálogo, que, sin embargo, ha pasado desapercibido para la mayoría de sus biógrafos y que pretendemos revalorizar a través de este artículo, repasando el contexto en el que se produjo y ofreciendo una descripción pormenorizada de los ejemplares que hoy en día se conservan, lo que permitirá relacionarlo con otros catálogos producidos en España y Europa en este mismo momento, aunque no es este el lugar para realizar un estudio comparativo.

La de El Escorial es la primera biblioteca que contó con un sistema de catálogos que iban más allá de los meros inventarios de manuscritos de época medieval (Sánchez Mariana, 1993, p. 213). El esfuerzo realizado por los jerónimos por estudiar los fondos dio lugar a catálogos como los de Arias Montano o el Padre Sigüenza, sin embargo, este impulso inicial fue perdiéndose a lo largo del s. XVII y no será hasta mediados del s. XVIII cuando se recupere, enmarcado en un proyecto más amplio. Como ha indicado Manuel Sánchez Mariana, el avance fundamental de la catalogación y descripción de manuscritos en España tuvo lugar en ese momento y estuvo circunscrito a la Real Biblioteca, antecedente de la actual Biblioteca Nacional, creada por Felipe V en 1711 (Sánchez Mariana, 1993, p. 213). Auspiciado por Carlos III, en su afán por presentar ante Europa una España con un alto nivel cultural, se creó un plan que tendía a "publicar repertorios de los principales fondos de manuscritos conservados en las bibliotecas reales" (Sánchez Mariana, 1993, p. 216).

En 1769 ve la luz el primer tomo del catálogo de los manuscritos griegos de la Real Biblioteca $^{2}$, elaborado por Juan de Iriarte (1702-1711), bibliotecario de la misma, que se-

${ }^{1}$ Guillermo Antolín trata la cuestión de las procedencias de las principales colecciones que constituyen los fondos de la biblioteca de El Escorial en: Antolín, 1923, pp. 1-305.

${ }^{2}$ J. de Iriarte (1769): Regiae Bibliothecae Matritensis codices graeci manuscripti, Matriti, ex Typographia Antonii Perez de Soto. El segundo tomo quedó inédito. La Biblioteca Nacional conserva el borrador, que está lejos de ser una obra acabada (Madrid. Biblioteca Nacional. Mss. 4656). 
gún parece estaba terminado ya desde 1742 (Sánchez Mariana, 1993, p. 214). Según muchos autores, este es considerado el mejor catálogo del s. XVIII. En él, se dividen las descripciones en dos partes, en primer lugar se señalan las características externas (materia, tamaño, número de folios, datación, tipo de letra, poseedor...) y en segundo lugar se describe el contenido, ofreciéndose siempre el incipit y explicit de cada una de sus partes. El autor trata de identificar el texto e intercala disertaciones sobre los aspectos que pueden dar lugar a dudas. Finalmente acompaña la obra de los índices pertinentes (Fernández Pomar, 1963, pp. 350-351). Iriarte fue con toda probabilidad el autor de la "Instrucción para formar el índice de manuscritos de la Real Biblioteca" (Sánchez Mariana, 1993, p. 215), del cual se conserva una copia en la Biblioteca Nacional fechada el 12 de agosto de $1762^{3}$. Esta instrucción sentaba las bases para una catalogación crítica y rigurosa, prescribiendo la necesidad de registrar el manuscrito hoja por hoja para elaborar una descripción adecuada, es decir, llevando a cabo un trabajo exhaustivo.

Unos años antes, en 1760, se había publicado el primer volumen del catálogo de manuscritos árabes de la biblioteca de $\mathrm{El} \mathrm{Escorial}^{4}$, redactado por el presbítero Miguel Casiri (1708-1792) y editado a cargo de la Real Biblioteca. En el catálogo, ordenado por materias y con entradas, en general, más escuetas que las de Iriarte, se indica, por lo que respecta a los datos externos, la escritura, el lugar, la fecha (según la Égira y la era cristiana), el copista, la procedencia y la materia, que solo se menciona cuando se trata de pergamino. No se incluye, en cambio, la foliación. A continuación se detalla el contenido, indicando el nombre del autor y los títulos con incipit y explicit en árabe. El segundo volumen, que apareció en 1770, presenta algunas modificaciones incluyendo análisis de tipo monográfico y edición de textos (Sánchez Mariana, 1993, p. 217).

La biblioteca de los escritores rabinos españoles ${ }^{5}$ de José Rodríguez de Castro (17301799), publicada entre 1781-1786, reúne la descripción de obras conservadas en diversas bibliotecas españolas, fundamentalmente en la Real Biblioteca y la biblioteca del monasterio de El Escorial. Más que un catálogo es un repertorio bio-bibliográfico, si bien, describe los manuscritos utilizados dando noticias del tamaño, la fecha, el tipo de escritura, descripciones de los textos, etc., es decir, recordando a un catálogo.

Además de los catálogos se publican otras obras importantes como la colección de poesías castellanas anteriores al s. XV ${ }^{6}$ de Tomás Antonio Sánchez (1732-1802) publicada en cuatro volúmenes entre 1779 y 1790 o la edición revisada de la Bibliotheca Hispana Nova de Nicolás Antonio (por Tomás Antonio Sánchez y José Antonio Pellicer) publicada en $1783^{7}$ y de la Bibliotheca Hispana Vetus del mismo autor (por obra de Francisco Pérez Bayer) que apareció en $1788^{8}$.

3 "Instrucción para formar el índice de los manuscritos de la Real Biblioteca" (Madrid. Biblioteca Nacional. Mss. 18.624). Este informe fue publicado por Vázquez de Parga, 1973, pp. 443-445.

4 M. Casiri (1760-1770): Bibliotheca arabico-hispana escurialensis sive librorum omnium Mss. quos arabice ab auctoribus magnam partem arabo-hispanis compositos Bibliotheca Coenobii Escurialensis complectitur crecensio et explanatio, Matriti, Antonius Pérez de Soto.

5 J. Rodríguez de Castro (1781): Biblioteca española, tomo I que contiene la noticia de los escritores rabinos españoles desde la época conocida de la literatura hasta el presente, Madrid, Imprenta Real.

6 T. Antonio Sánchez (1779): Colección de poesías castellanas, anteriores al siglo XV, Madrid, Imprenta de Joaquín Ibarra.

${ }^{7}$ N. Antonio (1783): Bibliotheca hispana nova sive hispanorum scriptorum qui ab anno MD ad MDCLXXXIV floruere notitia, Matriti, apud Joachimum de Ibarra.

${ }^{8}$ N. Antonio (1788): Bibliotheca hispana vetus, sive hispani scriptores qui ab Octaviani Augusti aevo ad annum Christi MD. Floruerunt, Matriti, Apud viduam et heredes D. Ioachimi Ibarrae. 
Como adelantábamos, dentro de esta tradición catalográfica, se incluye, sin duda alguna, el catálogo de códices latinos, castellanos, griegos y hebreos obra del valenciano Francisco Pérez Bayer. El eclesiástico forma parte de este grupo de bibliotecarios cuyo trabajo supuso, según Manuel Sánchez Mariana "un considerable avance de los estudios de erudición en España” (Sánchez Mariana, 1993, p. 220).

En 1761 Carlos III encargó a Francisco Pérez Bayer confeccionar el catálogo de manuscritos de la biblioteca del monasterio de El Escorial. La orden fue comunicada a Pérez Bayer por Ricardo Wall, ministro del Estado, a quien el primero contestó por carta el 11 de diciembre de 1761: "Con esto digo también a Vuestra Excelencia que luego después de la Epiphanía passaré, siendo Dios servido, al Escorial y formaré el índice de manuscritos latinos que allí hubiese con la exactitud posible, y con expresión del contenido de cada uno, de su antigüedad comprobada con la muestra del carácter en que estuviese escrito, y de las demás señas y circunstancias que le hiciesen recomendable; de suerte que si fuese del agrado de S.M. pueda desde luego imprimirse; y si no se huviesse ya encargado a otro la formación del índice de manuscritos hebreos, podré también trabajarlo"9.

La respuesta no se hizo esperar, el 18 de diciembre de 1761 Ricardo Wall escribía a Pérez Bayer autorizándole, por mandato real, a pasar a El Escorial en la fecha que proponía y formar los índices de los manuscritos latinos y hebreos y "que se le faciliten quantos medios discurra necesarios" 10 .

El eclesiástico valenciano llegó a El Escorial el 18 de enero de 1762 junto con su escribiente José Rodríguez Montalvo. Pérez Bayer solicitó la ayuda del calígrafo Francisco Javier Santiago Palomares ya que "quería publicar muestras de letras que justificasen sus apreciaciones y fueran también materiales exactos para estudiar paleografía" (Antolín, 1923, p. 324). Palomares se trasladó al monasterio el 15 de febrero de ese año, donde estuvo durante dos años junto a Pérez Bayer. Este último declara en su diario para la reforma de los colegios mayores, haber completado el catálogo de los manuscritos latinos, griegos y hebreos el año 1765: "Estaba yo también entonces [en 1763] allí [en el Escorial] formando de orden de S.M. los índices de los manuscritos latinos, griegos y hebreos de aquella Real Biblioteca, que concluí con el favor de Dios en el año 1765 y ocupan cinco gruesos tomos de a folio, sin contar otros tres en que copié varios tratados, sermones y opúsculos inéditos de algunos santos padres, filósofos y autores griegos" (Pérez Bayer, 2002, p. 682).

Este testimonio deja claro el número de volúmenes que ocupaba el catálogo, cinco, pues no todos los autores que mencionan el catálogo en sus repertorios coinciden ${ }^{11}$. Aparte quedarían los tres volúmenes que contenían la copia de textos diversos conservados en la biblioteca del monasterio.

Dicho año de 1765 se encontraba Pérez Bayer en Toledo y según su diario, estaba entonces "ocupado en dar la última mano a los índices de El Escorial, y habiendo, de resultas

\footnotetext{
9 Valladolid. Archivo General de Simancas. Secretaría de Guerra, suplemento, legajo 181.

10 Valladolid. Archivo General de Simancas. Secretaría de Guerra, suplemento, legajo 181.

11 Fuster menciona 5 tomos (Fuster, 1829, p. 28), mientras que Sempere y Guarinos solo 3 (Sempere y Guarinos, 1785, p. 199), Haenel y Miller hablan de 6 volúmenes en folio (Haenel, 1830, col. 922-923; Miller, 1848, p. XXVIII), Valentinelli menciona 5 volúmenes (Valentinelli, 1860, pp. 75-76) al igual que Fernández de Navarrete (Fernández de Navarrete, 1838, p. 53) y ya en el siglo XX, Antolín señala 8 volúmenes (Antolín, 1923, p. 327). En una obra más reciente, Justel Calabozo habla también de 8 volúmenes (Justel Calabozo, 1978, p. 98).
} 
de gran trabajo que en ello puse, enfermado gravemente de mal crónico" (Pérez Bayer, 2002, p. 682). Al parecer la redacción del catálogo había dado intensas fatigas al eclesiástico. Este tenía clara la intención de publicar el catálogo, como ya lo había manifestado en la carta antes mencionada dirigida a Ricardo Wall el 11 de diciembre de 1761. Guillermo Antolín transcribe el plan de impresión, conservado actualmente en el Archivo Histórico Nacional $^{12}$, que el marqués de Grimaldi, sucesor de Ricardo Wall, mostró al rey a propuesta de Francisco Pérez Bayer incluso antes de haber acabado la obra. La obra final contendría una gran cantidad de láminas: "Don Francisco Pérez Bayer me ha dicho que tenía ya casi en estado de concluir el primer tomo de la Biblioteca del Escorial que ha compuesto de orden de V.M. de suerte que dentro de muy pocos meses se podrá empezar a imprimir, y con muy corto intervalo tendrá en el mismo estado los demás tomos. Esta obra se compondrá de cuatro tomos ${ }^{13}$ en folio, de doscientos cincuenta pliegos poco más o menos cada uno. Contendrá entre todos unas ciento y sesenta láminas [...]” (Antolín, 1923, p. 325).

Pérez Bayer tiene clara la relación de su catálogo con el redactado por Casiri, cuyo primer volumen había aparecido unos años antes: "Para lo que toca a la impresión es menester hacerse cargo de que esta obra es como una seguida o consecuencia de la Biblioteca Arábiga de Casiri, que de orden de V.M. ha publicado la Biblioteca Real. Esta contiene la noticia y catálogo de todos los manuscritos Arábigos del Escorial: y la de Bayer se extiende a los Hebreos, Griegos, Latinos y Españoles; de donde se ve la unión que tienen una con otra, y que debe formar un mismo cuerpo" (Antolín, 1923, p. 325).

En este plan se prevé incluso el coste de la impresión ("ha calculado Bayer que podrá importar de catorce a quince mil pesos" (Antolín, 1923, p. 326), que correría a cargo del monarca, a quien iría dedicada la obra: "Si V.M. permite que salga esta obra a su Real nombre, como lo persuaden su contenido, la devoción del autor, y la generosidad de costearla, nada podrá hacerla más recomendable que el Augusto retrato de V.M. puesto a la frente de ella" (Antolín, 1923, p. 326). Sin embargo, todos estos planes cayeron en saco roto ya que finalmente, no sabemos con certeza porqué, la obra no llegó a imprimirse. Únicamente se han conservado dos tomos manuscritos en la Biblioteca del Real Monasterio de San Lorenzo de El Escorial.

Los dos tomos conservados en la Biblioteca de El Escorial, con las signaturas H-II-1 y H-II-2 (tomo uno y dos respectivamente) corresponden a los códices latinos y castellanos, cuyo título completo es: Regiae Bibliothecae Escurialensis manuscriptorum codicum latinorum et hispanorum quotquot in ea hoc anno M DCC LXII inventi fuere catalogus in quo quicquid in is atque eorum singulis continetur accuratissime describitur, indicata uniuscuiusque codicis aetate, iussu regio. Francisci Perezii Bayerii presbyteri valentini. Este título aparece en la portada del primer tomo, inserto en un dibujo, en cuya parte inferior derecha encontramos la siguiente nota: "Hecho siendo prior el reverendísimo padre fray Antonio del Valle"14.

A la portada le sigue directamente el índice de anónimos, Anonymorum index (fols. 3r$12 \mathrm{v}$ ). Las obras se presentan con el siguiente esquema: primero aparece la palabra anony$m i$ en letras mayúsculas, seguida del título, la signatura topográfica y el folio. Al principio

\footnotetext{
12 Madrid. Archivo Histórico Nacional. Estado, 2992.

13 Finalmente serán cinco, como hemos comentado anteriormente.

14 Prior de 1761 a 1768 (Quevedo, 1854, p. 258).
} 
se especifican lo que significan las siglas y abreviaturas utilizadas: Littera designat loculum quattuor pluteis constantem; numerus romanus, pluteus; arabicus, librorum ordinem et locum, quem singuli in pluteis occupant; postremus, autem omnium huius codicis paginam (fol. 3r). De tal modo que la signatura topográfica tiene la siguiente forma: $a$. II. Sub N. 12.; donde a designa el armario (littera designat loculum quattuor pluteis constantem), II indica el estante dentro del armario (pluteus) y sub N. 12, el número que ocupa el libro en el estante (librorum ordinem et locum, quem singuli in pluteis occupant). Al final se indican los folios en los que aparece la descripción completa de la obra, indicando que se trata del folio vuelto con la letra $b$ (por ejemplo, fol. 1 correspondería al recto y fol. $1 \mathrm{~b}$ al vuelto). Este sistema se mantendrá a lo largo de todo el catálogo.

A continuación (fols. 13r-42v) se incluye el índice alfabético de las obras incluidas en el catálogo, que comienza: Index codicum, quorum in ipsis certi auctores habentur aut de iis aliunde constat acta, allegationes, annalia, biblia, breviaria, comitia, concilia, consilia, constitutiones, decreta, edicta, fora, iura, leges, pragmaticae, sanctiones et statuta, quamvies de eorum auctoribus non constat hic requirenda sunt (fol. 13r). A continuación se insertan, a modo de prólogo, el estudio de dos de las obras más importantes, por su antigüedad, conservadas en la biblioteca de El Escorial: el Codex aureus ${ }^{15}$ y el De baptismo parvulorum $^{16}$ de san Agustín (fols. 43r- 58v). Sobre la segunda obra, Pérez Bayer afirma que el códice no es un autógrafo de san Agustín, como se había considerado hasta entonces, y lo data en el s. VI ${ }^{17}$. Dicho estudio comienza: "De binis eximis regii escurialensis coenibii codicibus, altero sancti Augustini de baptismo parvulorum, altero quatuor Evangeliorum litteris aureis exarato. Prologus" (fol. 43r).

Finalmente, desde el folio 61r al 261v se desarrolla el catálogo: Catalogus manuscriptorum codicum Regiae Bibliothecae Scorialensis, secundum ordinem quem singulis in pluteis atque scribis occupabant cum primum ad eam accesi paullo accuratior multoque plenior quam praecedens (fol. 61r). Este catálogo tiene su propia foliación, que comienza en el folio 61r del manuscrito. Las entradas están ordenadas según el lugar que ocupan las obras en la biblioteca (littera, pluteus, numerus). Este primer tomo comprende los armarios a, b, c, d y f, continuando en el segundo tomo, que incluye los armarios g, h, \& (Littera I cui in biblioteca respondet littera seu potius diagramma \&) y z (Littera K cui in Bibliotheca respondet Z). Cada armario está dividido en 4 estantes, en algunos casos 3, de forma que los primeros, comenzando por la parte inferior, contienen los volúmenes in folio, los segundos los volúmenes maiori forma, los terceros, quarta forma y los últimos, mediocri y quarta forma; lo que podemos conocer a partir de las entradas del catálogo. En total suman 829 entradas, 541 en el primer tomo y 288 en el segundo, que queda incompleto, termina con el número 2 del estante segundo del armario $\mathrm{Z}$.

Por lo que respecta a las descripciones, en primer lugar aparece el nombre del autor en mayúsculas, en segundo lugar el título, en tercer lugar se incluye una descripción más o menos pormenorizada del contenido y finalmente una descripción atendiendo al soporte, el tamaño, la fecha... Por ejemplo, en el fol. 61r-v vemos la siguiente entrada: S. AUGUSTINUS

15 Madrid. Real Biblioteca del Monasterio de El Escorial, Vitrinas 17 (Antolin, 1916, pp. 280-282 y 605-608).

${ }_{16}$ Madrid. Real Biblioteca del Monasterio de El Escorial, Vitrinas 25 (Justel Calabozo, 1978, p. 37).

17 El fragmento relativo a la obra De baptismo parvolurum de san Agustín fue reproducido por Guillermo Antolín, en su estudio sobre dicho códice en: Antolín, 1923b, pp. 380-395). 
in secundam psalmorum quinquagenam sive expositio psalmorum a quinquagessimo primo ad centessimum. In fine legitur: "Donatio huius codicis facta reverendo in Christo patre fratre Bartholomeo episcopo Elnensi Ecclesiae B. Eulaliae eiusdem civitatis Elnensis. Die 6 mensis junii, anno 1401". Codex membranaceus in folio circa dimidium saeculi decimi quarti scriptus.

El contenido de las descripciones varía, en unos casos, como el expuesto, es muy breve, mientras que en otros ocupa varias páginas e incluye pasajes transcritos de la obra en cuestión. Estos dos tomos fueron probablemente copiados por Santiago Javier de Palomares, quien según Emilio Cotarelo y Mori pasó dos años en El Escorial junto a Bayer "escribiendo cuatro gruesos volúmenes en folio y diversidad de letras" (Cotarelo y Mori, 1916, p. 136). Ambos presentan numerosas anotaciones al margen, muchas de las cuales son letra de Pérez Bayer, que contienen diversos tipos de aclaraciones, adiciones al texto y correcciones. Algunas de las notas, que se repiten constantemente, son: "esto aparte", "aquí la muestra de la letra", "véase quién fue este...". Por ejemplo, en el folio 123r aparece la siguiente nota "véase quien fue este Zucca en Chacón, porque el título está medio cortado por el que enquadernó el libro". En otro caso, en el fol. 64r se ha dejado un hueco en blanco en el texto y al lado se ha escrito "Aquí el escudo de armas", junto con el dibujo de una mano señalando el espacio donde debería incluirse dicho escudo.

Otro aspecto a tener en cuenta es la diferente factura material entre ambos volúmenes. El primero está encuadernado en piel y con los cortes teñidos de rojo, mientras que el segundo está encuadernado también en piel, con los cortes dorados y en un estado ligeramente peor que el anterior. En el primer volumen el texto está enmarcado en un recuadro (primero doble y a partir del folio 148r, simple), mientras que en el segundo volumen, este recuadro no aparece en todas las páginas y conforme va avanzando el texto, la escritura es menos cuidada y va variando de tamaño, especialmente en las últimas páginas en las que aparece casi sin separación entre líneas.

Estas últimas consideraciones nos indican que no se trata de un volumen acabado, sino que estamos ante un primer borrador que ha de completarse, siguiendo las anotaciones pertinentes para dar lugar a la obra definitiva que sería impresa.

Estos dos tomos manuscritos formaban parte del catálogo de los códices en latín y en vulgar, pero, ¿qué ocurrió con el resto? La totalidad de la obra permaneció en poder de Francisco Pérez Bayer e ingresó en la librería universitaria de Valencia, cuando este donó sus libros a la ciudad de Valencia en 1785 para formar con ellos una biblioteca pública en la Universidad. En este nuevo emplazamiento el catálogo no duraría mucho tiempo, ya que la Universidad sufrió un incendio en enero de 1812 causado por un bombardeo en el contexto de la Guerra de la Independencia, cuando prácticamente desapareció la biblioteca. Que los trabajos de Pérez Bayer en la biblioteca de El Escorial pasaron a formar parte de la biblioteca universitaria de Valencia, lo sabemos porque figuran en el inventario de los manuscritos donados por Francisco Pérez Bayer, redactado por el bibliotecario don Domingo Mascarós y Segarra, probablemente hacia $1785^{18}$. En este inventario localizamos las siguientes entradas, correspondientes a diferentes borradores y copias de los cinco tomos del catálogo de Pérez Bayer:

18 "Índice de los manuscritos que el Ilustrísimo Señor D. Francisco Pérez Bayer dio a la muy ilustre ciudad de Valencia, juntamente con su exquisita Bibliotheca para uso de la Universidad Literaria [ca. 1785]" Valencia. Biblioteca Histórica de la Universidad de Valencia, BH Ms. 0058. 
_"Borrador del catálogo de los códices manuscritos de la Real Biblioteca del Escurial que de orden de Su Majestad hizo don Francisco Pérez Bayer. Quatro tomos en folio menor con cubiertas en pastas de los quales los dos primeros tratan de los manuscritos latinos y españoles que se hallaron en el año 1762, el tercero de los manuscritos latinos, españoles y hebreos y el quarto de los códices griegos manuscritos" (fol. 4r-4v).

-“Copia en limpio del mismo catálogo. Quatro tomos en folio maior con la misma división que los anteriores con cubiertas de pasta" (fol. 4v).

_"Copia del quarto tomo del referido catálogo. Un lío sin enquadernar” (fol. 4v).

-"Borrador del quinto tomo que es el segundo de los griegos manuscritos del Escurial" (fol. 4v).

-"Borradores y apuntaciones del índice del Escurial y de otras obras del señor Bayer, un quaderno con cubiertas de pasta cuyo epígrafe por fuera es Aguirre Bibliotheca Hispana tom. 1" (fol. 17v).

Así mismo, en el fol. 38r, que forma parte de la segunda parte del inventario, correspondiente a los legajos y papeles, distribuidos en "líos", encontramos la siguiente referencia: "Borrador del índice general de los códices manuscritos de la Bibliotheca del Escurial, según el orden que tenía quando lo hizo el ilustrísimo señor don Francisco Pérez Bayer". Por otro lado, existen también diversas entradas que hacen referencia, probablemente, a los otros tres tomos redactados por Bayer en los que copia diversos textos conservados en la biblioteca de El Escorial, como son las siguientes:

-“Excerpta escurialensia. Primer tomo en folio menor con cubiertas de pasta, que contiene discursos sobre el Ecclesiastés, declaración del Psalmo 50 de sant Macario, homilía quinta de Antonio Agustín, censura sobre la doctrina de las calidades de los obispos y prelados, etcetera, etcetera" (fol. 4v-5r).

-“Nonnulla excerpta ${ }^{19}$ ex codicibus escurialensibus: scilicet de Hispanica versione Odissae Homeri, quae vulgo Gundisalvi Perezii nomine circumfetur, algunos epigramas de Joan Paecio de Castro, la traslación de algunas reliquias desde Toledo a Oviedo por la venida de los moros, vida de San Isidoro con un tratado de la venida de San Jaime Apóstol a España, vida y pasión de algunos mártires de España. Un quaderno a la rústica en folio de letra del señor Bayer" (fol. 9v-10r).

-“Lío 24. En este lío se contienen varios manuscritos $\operatorname{copiados}^{20}$ de algunos códices de la Real Bibliotheca del Escorial que son los siguientes: missa sancti Vincenti levitae et missa e codice gothico, expositio missae Beati Isidoro e codice vetustisimo anno 854 exarato, eiusdem ${ }^{21}$ Isidori collectum e binis codicibus, dimensio terrarum e codice vetustissimo seculo IX, Francisci Rocabertini de gloriae militaris ${ }^{22}$ palma, algunos presupuestos necesarios para deducir las etimologías castellanas y de otras lenguas más etimologías españolas con notas de Benito Arias Montano su autor el doctor Bartholome Valverde y Gandía, Cosmae Palmae Fonteii nonnulla e Thedoreto Cyrri epistola in latinum conversa y según nota del ilustrísimo Bayer la oración adversus eos qui veritatis cognitionem a multitudinis adversus eos qui veritatis cognitionem statuunt sua quinque fide contentum esse debere fueron pronunciadas por el referido Concilio de Trento, algunos tratados de

\footnotetext{
19 En el original: exerpta.

20 En el original: codiados.

21 En el original: eyusdem.

22 En el original: milistaris.
} 
Athanasio que en sentencia de Bayer fueron traducidos al latín por Pedro de Valencia, $b i$ bliotheca Sancti Isidori Poematia e codice gothico vetustissimo" (fol. 38v-39r).

Por otro lado, en la propia biblioteca de El Escorial se conservan varios documentos prueba del trabajo de Pérez Bayer. El manuscrito con signatura H-I-11 (2 $2^{\circ}$, que corresponde a un volumen facticio, contiene entre los folios $184 \mathrm{r}$ y $237 \mathrm{v}$ lo que parece ser un borrador del catálogo de los manuscritos latinos y castellanos de Francisco Pérez Bayer, escrito de su propia mano. Comienza: "Littera I cui in Bibliotheca respondet littera seu potius diagramma \&", en una nota en el margen superior derecho se puede leer, "II Tomi - aquí faltan los dos estantes $g$ y $h$ ".

Otro manuscrito interesante es el H-I-10 $\left(1^{\circ}\right)$ que contiene "el resultado del cotejo practicado por el inventario formado por D. Francisco Pérez Bayer hasta donde alcanzan los dos tomos que de él existen, y el inventario de los demás códices manuscritos en castellano, latín y otros idiomas que no han podido cotejarse, por no haber inventario alguno que los comprendiese" (fols. 158r-162v) y el "inventario de los códices manuscritos y castellanos, etc. que existen en la Real Biblioteca del Escorial, desde el pluteo $2^{\circ}$ del estante señalado con las letras $\mathrm{k} \mathrm{o} \mathrm{z} \mathrm{que} \mathrm{es} \mathrm{hasta} \mathrm{donde} \mathrm{llegan} \mathrm{los} \mathrm{tomos} \mathrm{del} \mathrm{catálogo} \mathrm{formado} \mathrm{por}$ Francisco Pérez Bayer en el año 1762" (fols. 162r-186v). Estos trabajos fueron redactados probablemente por el padre Félix Rozanski, bibliotecario desde 1875 hasta 1884 (Justel Calabozo, 1978, pp. 111-112), que fue quien formó el volumen facticio del que forman parte. Este mismo manuscrito contiene otros listados de libros similares como el "Cotejo practicado por el inventario del padre fray Juan de Cuenca hasta donde alcanzan los veinte tomos que de él existen..." (fols. 194r-200v).

Por otro lado, el Archivo Histórico Nacional conserva un cuadernillo que contiene, según reza el encabezamiento, un extracto de "lo perteneciente a España hasta la página 153 del tomo $1^{\circ}$ del catalogus de Bayer"23. Al texto del catálogo, se agregan diversos comentarios sobre su contenido, si bien no aportan mucha más información. Este mismo documento es el que fue reproducido posteriormente en la Revista de Archivos, Bibliotecas y Museos por Francisco García Fresca ${ }^{24}$.

Los manuscritos hebreos ocuparían el $3^{\circ}$ tomo (Fuster, 1829, p. 28), que no se ha conservado. José Rodríguez de Castro, en el prólogo a su biblioteca de los escritores rabinos españoles, dice haber consultado para su estudio la biblioteca personal de Francisco Pérez Bayer "y aún sus mismos manuscritos originales" y añade que: "por los borradores que trabajó este infatigable erudito para formar un índice de los libros de la Real Biblioteca del Monasterio de S. Lorenzo del Escorial, adquirí noticia de los muchos y apreciables manuscritos que había en ella de obras de rabinos españoles, y otras pertenecientes a esta clase de literatura" (Rodríguez de Castro, 1781, fol. 7v). Testimonio que no deja de ser una prueba de la redacción por parte de Pérez Bayer de un catálogo de obras hebreas, o al menos de la intención de redactarlo.

Por lo que respecta al catálogo de manuscritos griegos, que correspondería al $4^{\circ}$ tomo (Fuster, 1829, p. 28), Charles Graux en su ensayo sobre los orígenes del fondo griego de El Escorial, niega que Pérez Bayer lo hubiera redactado (Graux, 1982, p. 28). Raimundo González Andrés, en cambio, menciona el "Catálogo de los manuscritos griegos del Esco-

23 Madrid. Archivo Histórico Nacional. Estado, 2630, exp. 91.

${ }^{24}$ F. García Fresca (1782): "Extracto del catálogo de manuscritos de la Biblioteca del Escorial hecho por D. Francisco Pérez Bayer”, Revista de Archivos, Bibliotecas y Museos, II, 218-222. 
rial, 3 tomos en folio: obra que existe manuscrita en la misma biblioteca" (González Andrés, 1866, pp. 10-11), afirmación que no parece del todo fundada, ya que los códices griegos no ocuparían tres volúmenes, sino solo uno, y autores anteriores mencionan ya la existencia de únicamente dos tomos conservados en la biblioteca de El Escorial, mientras que el resto habrían perecido en el incendio de la Universidad de Valencia ${ }^{25}$. Pero lo que más interesa, al margen de esto último, es que D.G. Moldenhawer y T.C. Tyschen elaboraron un catálogo de los códices griegos de El Escorial en 1784, catálogo que tampoco llegaría a imprimirse. Para su redacción utilizaron como base el de Pérez Bayer, al que se refieren constantemente con la sigla $\mathrm{B}$, y de forma más explícita en la entrada correspondiente a la liturgia de San Basilio (Revilla, 1936, p. XXII). Este catálogo fue extractado por Ada Adler en el Catalogue supplementaire des manuscrits grecs de la Bibliotheque Royale de Copenhague de 1916, lo que nos lleva a pensar que posiblemente Graux desconociera los trabajos de Pérez Bayer.

A modo de conclusión, consideramos que la repetida alusión al catálogo de Pérez Bayer por los distintos autores que han estudiado los fondos de la biblioteca de El Escorial, la conservación de los volúmenes manuscritos que permanecen inéditos en dicha biblioteca y los demás hallazgos que hemos mencionado, son prueba suficiente de que efectivamente Francisco Pérez Bayer redactó el catálogo de los códices latinos, castellanos, griegos y hebreos de la biblioteca de El Escorial y de que de haberse publicado, hubiera estado entre los principales trabajos de erudición y catalogación de su tiempo. Como adelantábamos, este catálogo forma parte de una tradición catalográfica más amplia de la que Pérez Bayer era conocedor y en la que participó, a pesar de que por razones que aún desconocemos, pero probablemente ajenas a los resultados de su trabajo, su catálogo no llegó a ver la luz, permaneciendo incompleto e inédito en la biblioteca del Real Monasterio de El Escorial.

\section{BIBLIOGRAFÍA}

ANDRÉS, G. de. (1985): "Perfil histórico de la Real Biblioteca de El Escorial”, en: El Escorial en la Biblioteca Nacional, Biblioteca Nacional, diciembre 1985-enero 1986 [Madrid], Dirección General del Libro y Bibliotecas, 559-566.

ANTOLÍN, G. (1911): Catálogo de los Códices Latinos de la Real Biblioteca de El Escorial, Madrid, Imprenta Helénica, vol. II, 596 p.

ANTOLÍN, G. (1916): Catálogo de los Códices Latinos de la Real Biblioteca de El Escorial, Madrid, Imprenta Helénica, vol. IV, 610 p.

ANTOLÍn, G. (1923): Catálogo de los Códices Latinos de la Real Biblioteca de El Escorial, Madrid, Imprenta Helénica, vol. V, 512 p.

ANTOLÍN, G. (1923b): “El códice ‘De baptismo parvulorum' de san Agustín, que se conserva en El Escorial", Boletín de la Real Academia de la Historia, 83, 378-403.

ANTONIO SÁNCHEZ, T. (1779): Colección de poesías castellanas, anteriores al s. XV, Madrid, Imprenta de Joaquín Ibarra, 404 p.

ANTONIO, N. (1783): Bibliotheca hispana nova sive hispanorum scriptorum qui ab anno MD ad MDCLXXXIV floruere notitia, Matriti, apud Joachimum de Ibarra, $475 \mathrm{p}$.

ANTONIO, N. (1788): Bibliotheca Hispana Vetus, sive hispani scriptores qui ab Octaviani Augusti aevo ad annum Christi MD. floruerunt, Matriti, Apud viduam et heredes D. Ioachimi Ibarrae. $622 \mathrm{p}$.

${ }^{25}$ Entre ellos, Haenel (1848, col. 922-923) y Fernández de Navarrete (1837, p. 53). 
CASIRI, M. (1760-1770): Bibliotheca arabico-hispana escurialensis sive Librorum omnium Mss. quos arabice ab auctoribus magnam partem arabo-hispanis compositos Bibliotheca Coenobii Escurialensis complectitur crecensio et explanatio, Matriti, Antonius Pérez de Soto, 2 vols.

COTARELO Y MORI, E. (1916): Diccionario biográfico y bibliográfico de calígrafos españoles, Madrid, Imprenta de la "Revista de Archivos, Bibliotecas y Museos", vol. II, 347 p.

FERNÁNDEZ DE NAVARRETE, M. (1838): Discurso leído a la Real Academia de la Historia en junta de 24 de noviembre de 1837, Madrid, Oficina de D. Eusebio Aguado impresor, 55 p.

FERNÁNDEZ POMAR, J. (1963): "La catalogación del fondo griego de la Biblioteca Nacional", Helmantica, 45, 341-380.

FUSTER, J. P. (1829): Elogio histórico y bibliográfico del ilustrísimo señor don Francisco Pérez Bayer, Valencia, Ildefonso Mompié, $40 \mathrm{p}$.

GARCÍA FRESCA, F. (1782): "Extracto del catálogo de manuscritos de la Biblioteca del Escorial hecho por D. Francisco Pérez Bayer", Revista de Archivos, Bibliotecas y Museos, II, 218-222.

GONZÁLEZ ANDRÉS, R. (1866): Breve exposición de la literatura griega, Madrid, $2^{\mathrm{a}}$ ed., 216 p.

GRAUX, C. (1982): Los orígenes del fondo griego del Escorial. Edición y traducción por Gregorio de Andrés, Madrid, Fundación universitaria Española, 578 p.

HAENEL, G. F. (1830): Catalogi librorum manuscriptorum, qui in bibliothecis Galliae, Helvetiae, Belgii, Britanniae M., Hispaniae, Lusitaniae asservantur, Lipsiae, sumtibus I.C. Hinrichs, 1238 col.

IRIARTE, J. de (1769): Regiae Bibliothecae Matritensis codices graeci manuscripti, Matriti, ex typographia Antonii Perez de Soto, $579 \mathrm{p}$.

JUSTEL CALABOZO, B. (1978): La Real Biblioteca de El Escorial y sus manuscritos árabes: Sinopsis histórico-descriptiva, Madrid, Instituto Hispano-Árabe de Cultura, 324 p.

MILLER, E. (1848): Catalogue des manuscrits grecs de la bibliothèque de l'Escurial, Paris, Imprimerie Nationale, $562 \mathrm{p}$.

PÁEZ DE CASTRO, J. [1749?]: Memorial a Felipe II sobre la utilidad de juntar una buena biblioteca, copiado por Blas Antonio Nasarre. [S.1.], [s.n.], 57 p.

PÉREZ BAYER, F. (2002): Diario histórico de la reforma de los seis colegios mayores de Salamanca, Valladolid y Alcalá. Edición y estudio preliminar de Antonio Mestre Sanchis, Jorge A. Catalá Sanz, Pablo Pérez García [Valencia], Biblioteca Valenciana, 885 p.

QUEVEDO, J. (1854): Historia del Real Monasterio de San Lorenzo del Escorial, Madrid, Imprenta, Fundición y Librería de D. Eusebio Aguado, 380 p.

REVILlA, A. (1936): Catálogos de los Códices Griegos de la Biblioteca de El Escorial, Madrid, Imprenta Helénica, vol. I, 560 p.

RODRÍGUEZ DE CASTRO, J. (1781): Biblioteca española, tomo I que contiene la noticia de los escritores rabinos españoles desde la época conocida de la literatura hasta el presente, Madrid, Imprenta Real, 2 vols.

SÁNCHEZ MARIANA, M. (1993): "La catalogación de manuscritos en torno a la biblioteca real (1712-1836)", en: Gimeno Blay, F. (ed.), Erudición y discurso histórico: las instituciones europeas (ss. XVIII-XIV), València, Seminari Internacional d'Estudis sobre la Cultura Escrita, 213222.

SEMPERE Y GUARINOS, J. (1785): Ensayo de una biblioteca española de los mejores escritores del reynado de Carlos III, Madrid, en la Imprenta Real, vol. I, 245 p.

VALENTINELLI, G. (1860): Delle Biblioteche della Spagna, Wien, aus der K.H. Hof- und Staatsdruckerei, $177 \mathrm{p}$.

VÁZQUEZ DE PARGA, L. (1973): “Algunas noticias sobre la organización y primera catalogación de la sección de manuscritos de la Biblioteca Nacional", en: Homenaje a Federico Navarro: miscelánea de estudios dedicados a su memoria, Madrid, ANABA, 435-445.

ZARCO CUEVAS, J. (1924): Catálogo de los manuscritos castellanos de la Real Biblioteca de El Escorial, Madrid, Imprenta Helénica, vol. I, 370 p. 